\title{
Transforming capacity-strengthening in an era of sustainable development
}

\author{
Anne Christine Stender Heerdegen ${ }^{1,2}$ (])
}

Received: 17 April 2020/Revised: 15 September 2020 / Accepted: 20 September 2020/ Published online: 22 October 2020

(C) The Author(s) 2020

District health managers (DHMs) operate and manage most public health care facilities in the health systems of many low- and middle-income countries (LMICs). They must turn national health policies and human, material, and financial resources into accessible high-quality health services (Heerdegen et al. 2020a). To improve district health services in many LMICs, the capacity of DHMs must be strengthened (Dovlo 2016).

Capacity-strengthening is multi-dimensional and includes "efforts towards strengthening the ability of individuals, organizations, or institutions to perform appropriate functions effectively, efficiently, and sustainably" (Bates et al. 2011). Many district management strengthening interventions focus on strengthening the DHMs' individual competency through formal learning, e.g., classroom training (Martineau et al. 2018). Improving the skills, knowledge, and attitudes of DHMs increases their ability to carry out their job, but their performance also depends on the environment in which they operate (Heerdegen et al. 2020b). In Ghana, for example, DHMs face resource uncertainty (human, material and financial), have limited decision-making authority, and operate under budgetary restrictions in challenging working conditions (Heerdegen et al. 2020b). No matter how competent the DHMs are, these factors affect their ability to carry out responsibilities and limits their opportunity to be innovative and agile in responding to district health needs (Heerdegen et al. 2020b).

This Editorial is part of the series "Young Researcher Editorial", a training project of the Swiss School of Public Health.

Anne Christine Stender Heerdegen annechristine.heerdegen@swisstph.ch

1 Swiss Tropical and Public Health Institute, Basel, Switzerland

2 University of Basel, Basel, Switzerland
Capacity should be viewed systemically because it is a product of a complex combination of factors (i.e., individual competencies, resources, policies) in a specific context (Aragón and Giles Macedo 2010). Efforts to strengthen capacity must be based on a comprehensive understanding of the context in which DHMs are embedded. Gaining this understanding requires actively involving local stakeholders, including DHMs, who can identify bottlenecks and inefficiencies in organizational processes, policies, or individual competencies (de Savigny and Adam 2009). They can provide expert knowledge about management capacity gaps, and suggest ways to fill these sustainably, in ways appropriate to their culture and context.

Actively involving local stakeholders in a participatory approach to capacity-strengthening is made easier by the use of tools that encourage users to think thematically, like social network analyses, causal loop diagrams, problem trees, and process mapping (de Savigny and Adam 2009). Process mapping has for example helped in effectively identifying inefficiencies in health workforce managerial practices in Ghana (Heerdegen et al. 2019). Actively involving local stakeholders can also make it easier for implementers of management strengthening efforts to identify existing national, regional, and local strategies, policies, and plans that contribute to strengthen management capacity.

Enhancing "international support for implementing effective and targeted capacity-building in developing countries to support national plans to achieve the SDGs" is a Sustainable Development Goal (SDG 17: 'Partnerships for Sustainable Development'), but bilateral development partners who are responsible for capacity-building initiatives in LMICs often disregard country policies and plans (United Nations 2019). This is problematic as capacitybuilding efforts are less sustainable when not integrated into the national health system (Bates et al. 2011). Moreover, it may create perpetual dependency on development 
partners (Brinkerhoff 2007). Development partners may bypass national plans to strengthen capacity because they are unaware of them - a situation that underscores the importance of collaborating closely with local stakeholders.

A systemic and participatory approach to strengthening management capacity may be more time-consuming than traditional competency development interventions, as it requires building relationships and a level of trust that facilitates effective partnerships with local stakeholders. Moreover, contextual and organizational factors like policies, structures, and resource availability that undermine a DHM's ability and willingness to carry out their duties are more complex to address compared with individual competencies (Brinkerhoff 2007). Nonetheless, without collaborating with local stakeholders, interventions are unlikely to be sustainable, and if the system in which the DHM is embedded does not change, many competent DHMs will still have limited capacity to carry out their responsibilities effectively and efficiently. In turn, this may limit the public's access to essential and responsive health services at the district level.

Targeting competencies alone is insufficient to develop sustained improvements in management capacity. Since DHMs' capacity is determined by a complex interaction of individual, organizational, and contextual factors, future capacity-strengthening initiatives should take on a systemic approach that utilizes tools to encourage systemic thinking, and encourages close collaboration with relevant local stakeholders (Heerdegen et al. 2020b).

Funding Horizon 2020 European Commission, PERFORM2Scale (Grant Number: 733360).

\section{Compliance with ethical standards}

Conflict of interest The author declares no conflict of interest.

Open Access This article is licensed under a Creative Commons Attribution 4.0 International License, which permits use, sharing, adaptation, distribution and reproduction in any medium or format, as long as you give appropriate credit to the original author(s) and the source, provide a link to the Creative Commons licence, and indicate if changes were made. The images or other third party material in this article are included in the article's Creative Commons licence, unless indicated otherwise in a credit line to the material. If material is not included in the article's Creative Commons licence and your intended use is not permitted by statutory regulation or exceeds the permitted use, you will need to obtain permission directly from the copyright holder. To view a copy of this licence, visit http://creativecommons. org/licenses/by/4.0/.

\section{References}

Aragón AO, Giles Macedo JC (2010) A 'systemic theories of change'approach for purposeful capacity development. IDS Bull 41(3):87-99. https://doi.org/10.1111/j.1759-5436.2010.00140.x

Bates I, Taegtmeyer M, Squire SB, Ansong D, Nhlema-Simwaka B, Baba A et al (2011) Indicators of sustainable capacity building for health research: analysis of four African case studies. Health Res Policy Syst 9(1):14. https://doi.org/10.1186/1478-4505-9-14

Brinkerhoff DW (2007) Developing capacity in fragile states. Public Adm Dev 30:66-78. https://doi.org/10.1002/pad.545

de Savigny D, Adam T (eds) (2009) Systems thinking for health systems strengthening. World Health Organization, Geneva

Dovlo D (2016) Does management really matter? And if so, to who?: Comment on " management matters: a leverage point for health systems strengthening in global health". Int J Health Policy Manag Sci 5(2):141-143. https://doi.org/10.15171/ijhpm.2015. 204

Heerdegen ACS, Bonenberger M, Aikins M, Schandorf P, Akweongo P, Wyss K (2019) Health worker transfer processes within the public health sector in Ghana: a study of three districts in the Eastern Region. Hum Resour Health 17(1):45. https://doi.org/10. 1186/s12960-019-0379-z

Heerdegen ACS, Aikins M, Amon S, Agyemang SA, Wyss K (2020a) Managerial capacity among district health managers and its association with district performance: a comparative descriptive study of six districts in the Eastern Region of Ghana. PLoS ONE. https://doi.org/10.1371/journal.pone.0227974

Heerdegen ACS, Gerold J, Amon S, Agyemang SA, Aikins M, Wyss K (2020b) How does district health management emerge within a complex health system? Insights for capacity strengthening in Ghana. Front Public Health. https://doi.org/10.3389/fpubh.2020. 00270

Martineau T, Raven J, Aikins M, Alonso-Garbayo A, Baine S, Huss R et al (2018) Strengthening health district management competencies in Ghana, Tanzania and Uganda: Lessons from using action research to improve health workforce performance. BMJ Glob Health. https://doi.org/10.1136/bmjgh-2017-000619

United Nations (2019) Special edition: progress towards the sustainable development goals. United Nations Economic and Social Council. https://unstats.un.org/sdgs/files/report/2019/secretarygeneral-sdg-report-2019-EN.pdf. Accessed 14 Sept 2020.

Publisher's Note Springer Nature remains neutral with regard to jurisdictional claims in published maps and institutional affiliations. 